\title{
Tecnologia da informação e desempenho da gestão documental em uma Universidade Federal
}

\author{
Sílvia Cintra Borges Morais' \\ http:/ / orcid.org/ 0000-0001-5507-3969 \\ Clarissa Carneiro Mussi " \\ http:// orcid.org/ 0000-0003-0367-4345 \\ Maurício Andrade de Lima'"I \\ http:// orcid.org/ 0000-0002-4287-5791 \\ Marli Dias de Souza Pinto'v \\ http:// orcid.org/0000-0002-0483-3988 \\ ' Universidade do Sul de Santa Catarina, SC, Brasil. \\ Mestre em Administração. \\ "Universidade do Sul de Santa Catarina, SC, Brasil. \\ Docente no Programa de Pós-graduação em Administração. \\ III Universidade do Sul de Santa Catarina, SC, Brasil. \\ Docente no Programa de Pós-graduação em Administração. \\ IV Universidade Federal de Santa Catarina, SC, Brasil. \\ Docente no Programa de Pós-graduação em Ciência da Informação.
}

http:/ / dx.doi.org/ 10.1590/ 1981-5344/ 3547

Esta pesquisa investigou a percepção de gestores e usuários sobre a influência da tecnologia da informação no desempenho da gestão documental em uma universidade federal. A elaboração da estrutura conceitual de análise foi guiada pelos fundamentos do Balanced Scorecard. Metodologicamente, a pesquisa caracterizou-se como qualitativa, do tipo estudo de caso. Entrevistas semiestruturadas, observação participante e pesquisa documental foram utilizadas para a coleta dos dados. Como resultados identificou-se um amplo espectro de possibilidades de contribuição da tecnologia da 
informação. De forma geral, estas possibilidades estão relacionadas à satisfação dos usuários, à qualidade dos processos documentais, à capacidade de aprender, inovar, e melhorara gestão documental, e à otimização dos recursos financeiros da gestão documental e consequentemente da organização. $\mathrm{Na}$ universidade pesquisada, esta contribuição é parcial e incipiente. A maximização do apoio da tecnologia da informação ao desempenho da gestão documental depende de questões de natureza humana e social, além daquelas de ordem tecnológica.

Palavras-chave: Gestão documental, Arquivo, Desempenho, Tecnologia da Informação, Balanced Scorecard.

\section{Information technology and document management performance at a Federal University}

This research investigated the perception of managers and users about the influence of information technology on the document management performance at a federal university. The conceptual frame work of analysis was guided by he foundations of the Balanced Scorecard. Methodologically, the research was characterized as qualitative and case study type. Semi structured interviews, participant observation and documentary research were used to collect the data. As results, a broad spectrum of possibilities of contribution of the information technology was identified. In general, these possibilities are related touser satisfaction, the quality of documentary processes, the ability to learn, innovate and improve the document management and, the optimization the financial resources of document management and consequently of the organization. This contribution is partial and incipient at the researched university, The maximization of the support of information technology to the document 
management performance depends on human and social questions, besides those of a technological nature.

Keywords: Document Management, Archive, Performance, Information Technology, Balanced Scorecard.

Recebido em 01.06.2018 Aceito em 30.03.2020

\section{I ntrodução}

Os documentos são inerentes às instituições. Vários processos institucionais são mediados por documentos. Cada vez mais torna-se necessário que haja domínio da massa documental nas instituições com o objetivo de agilizar o fluxo de processos (SANTOS; FLORES, 2015). Como argumenta Rocco (2013), o aumento da produção documental se deu por uma mudança de paradigma, na qual a informação passou a ser o centro das atividades desenvolvidas pela sociedade, necessitando-se de abordagens para tratar as informações e consequentemente os documentos onde as informações encontram-se registradas.

A Gestão Documental (GD) vem sendo estudada e discutida nas Instituições de Ensino Superior (IES), públicas e privadas (MORENO, 2008; CARPES, CASTANHO, 2014). Neste contexto, os objetivos da GD constituem-se em abastecer a instituição de todas as informações necessárias para a tomada de decisões, racionalizar a produção de documentos e preservar os documentos probatórios/ históricos (CISCATO et al., 2011). Portanto, toda a documentação produzida e recebida pela IES, até mesmo aquela procedente de ambientes digitais, constitui-se objeto de gestão (GERONIMO, 2014). Tanto a documentação acadêmica, atividade-fim, quanto à documentação administrativa, atividade-meio, precisam receber o mesmo tratamento documental e seus prazos de guarda serem respeitados de acordo com as tabelas de temporalidade de documentos (RONCAGLIO; SZVARÇA; BOJ ANOSKI, 2004).

Com a elevada produção documental, a tecnologia da informação (TI) tornou-se fundamental para auxiliar as atividades da GD (SANTOS; FLORES, 2015). "O avanço tecnológico mudou radicalmente os mecanismos de registro e de comunicação da informação nas instituições e, consequentemente, seus arquivos também mudaram" (RONDINELLI, 2005, p. 24). As principais vantagens da TI como ferramenta de apoio à GD podem ser apresentadas como: redução de custos; criação e digitalização de documentos; acesso remoto, rápido e simultâneo; segurança da informação e preservação de documentos originais (FELIX; SILVA, 2010). Silva e Fleury (2003) destacam que cada vez mais e com 
maior assiduidade as IES utilizam a TI nas suas atividades acadêmicas e administrativas, entretanto problemas técnicos, investimentos, burocracia e a própria instituição com falta de capacitação dos servidores impedem a utilização efetiva das novas tecnologias.

Os investimentos em $\mathrm{Tl}$ e seu impacto no desempenho organizacional como um todo vêm sendo estudado por vários pesquisadores, pois embora se invista consideravelmente em $\mathrm{TI}$, não é fácil apresentar seus efeitos na instituição, principalmente os impactos estratégicos e econômicos (ALBERTIN; ALBERTIN, 2008; MEIRELES; ROCHA; CENDÓN, 2012; WU; CHEN, 2014). Historicamente, o processo de avaliação de desempenho organizacional permaneceu ligado fundamentalmente às perspectivas financeiras, que apresentam os resultados de uma organização a partir de cálculos de lucros, renda e aumento patrimonial (SANTOS, 2010). Na conjuntura organizacional atual, olhar somente para avaliações financeiras pode apresentar dados enganosos e insuficientes para melhoria contínua e inovação (SOUZA; CORREA, 2014). Nesta perspectiva, surgem propostas de sistemas de avaliação de desempenho organizacional incorporando outros indicadores, além dos tradicionais financeiros, como por exemplo, o tradicional e conhecido Balanced Scorecard (BSC) (KAPLAN; NORTON, 1992).

Mais especificamente, no que se refere ao desempenho da gestão documental e dos serviços documentários é defendido que a sua avaliação deve estar direcionada também a outras perspectivas, além da financeira, como por exemplo, à satisfação dos usuários e à qualidade dos processos referentes aos serviços (BRIAND et al, 2002; POMBAL, 2009). Dessa forma, delineou-se para investigação o seguinte problema de pesquisa: como gestores e usuários percebem a influência da tecnologia da informação no desempenho da gestão documental em uma universidade federal? Embora haja um conjunto de estudos para investigar a GD em instituições de ensino superior no contexto brasileiro (ANDRADE, 2017; COSTA; SILVA, 2015; CISCATO et al. 2011, CARPES; CASTANHO, 2014; BAHIA; BLATTMANN, 2011; SILVA; SANTOS; VIERO, 2009; GERONIMO, 2014) e estes estudos venham colaborando significativamente para a compreensão das complexidades e desafios da área, estudos de avaliação do desempenho da GD, sob a perspectiva teórica do BSC, são mais raros. Neste sentido, esta pesquisa contribui com a identificação de critérios para a avaliação do desempenho da gestão documental em com a análise do apoio da $\mathrm{TI}$ a estes critérios.

A próxima seção deste trabalho, seção 2, aborda o desenvolvimento de uma estrutura de análise a partir dos fundamentos teóricos do estudo. $\mathrm{Na}$ seção 3 discorre-se sobre o delineamento metodológico da pesquisa. $\mathrm{Na}$ seção 4 aborda-se os seus resultados e por fim, na seção 5, são apresentadas as considerações finais. 


\section{Delineando uma estrutura de pesquisa a partir da literatura}

O desenvolvimento da estrutura para analisar o papel da $\mathrm{TI}$ no desempenho da GD pautou-se no Balanced Scorecard e seus princípios, bem como nos fundamentos teóricos da GD. A opção pelo BSC apoia-se no fato desta ferramenta considerar outras perspectivas de desempenho, além da financeira, bem como, na sua proposição a partir da estratégia organizacional. Assim, as categorias de análise principais que compõem esta estrutura correspondem às quatro perspectivas do BSC alinhadas à instituições públicas, denominadas neste estudo de perspectivas de análise. Com o objetivo de descrever estas perspectivas no contexto da gestão documental e identificar os seus elementos constituintes, inicialmente foram elaboradas perguntas norteadoras associadas a cada uma das perspectivas, como apresenta o Quadro 1.

Quadro 1 - Perguntas norteadoras e perspectivas de desempenho da gestão documental.

\begin{tabular}{|l|l|l|}
\hline $\begin{array}{l}\text { Perspectivas de } \\
\text { análise }\end{array}$ & Perguntas Norteadoras & Definição da perspectiva \\
\hline Usuários & $\begin{array}{l}\text { Como os serviços/produtos da gestão } \\
\text { documental poderiam satisfazer seus } \\
\text { usuários? }\end{array}$ & $\begin{array}{l}\text { Refere-se aos usuários dos serviços/produtos } \\
\text { resultantes da gestão documental e abrange as } \\
\text { suas necessidades. }\end{array}$ \\
\hline $\begin{array}{l}\text { Processos } \\
\text { internos }\end{array}$ & $\begin{array}{l}\text { Em que processos da gestão } \\
\text { documental devemos buscar o nível de } \\
\text { excelência para satisfazermos as as } \\
\text { necessidades dos usuários? }\end{array}$ & $\begin{array}{l}\text { Representa os processos internos críticos da } \\
\text { gestão documental para a concretização dos } \\
\text { objetivos e satisfação das necessidades dos } \\
\text { seus usuários. }\end{array}$ \\
\hline $\begin{array}{l}\text { Aprendizagem } \\
\text { Crescimento }\end{array}$ & $\begin{array}{l}\text { Como sustentaremos a capacidade de } \\
\text { aprender, inovar e melhorar a gestão } \\
\text { documental? }\end{array}$ & $\begin{array}{l}\text { Compreende os recursos e as competências da } \\
\text { organização que sustentam a sua capacidade } \\
\text { de aprender, crescer e inovar na GD }\end{array}$ \\
\hline Financeira & $\begin{array}{l}\text { Como deveríamos otimizar os recursos } \\
\text { financeiros da gestão documental e } \\
\text { consequentemente da organização? }\end{array}$ & $\begin{array}{l}\text { Visa sustentar os objetivos das outras } \\
\text { perspectivas e otimizar os recursos financeiros } \\
\text { da gestão documental e da organização. }\end{array}$ \\
\hline
\end{tabular}

Fonte: Adaptado de Kaplan e Norton (1992).

As perguntas norteadoras contribuíram para a definição de objetivos estratégicos para cada perspectiva e para a elaboração do mapa estratégico da GD, conforme a Figura 1. 
Figura 1 -Perspectivas de análise, objetivos estratégicos e suas relações de causa e efeito.

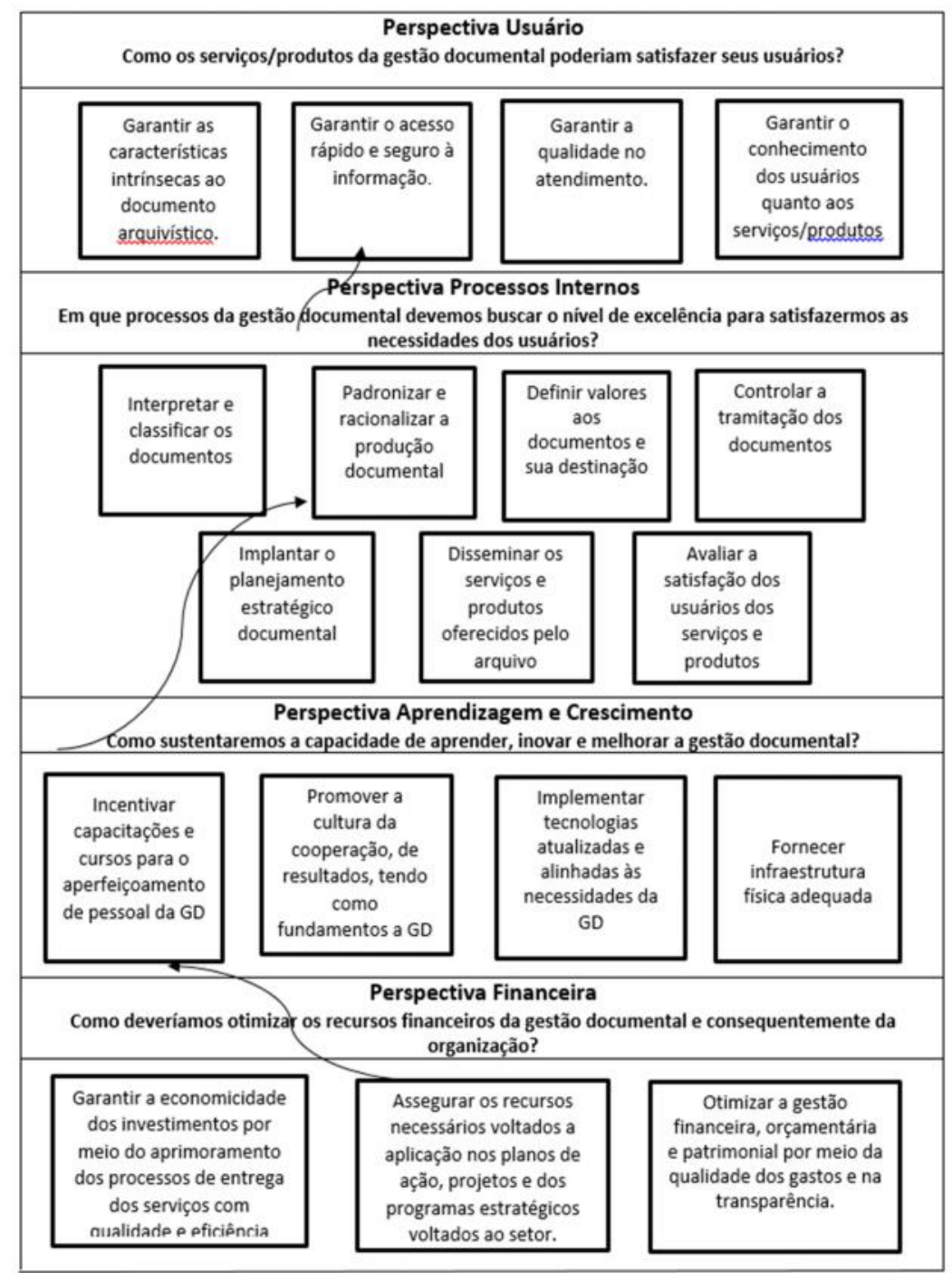

Fonte: Adaptado de Kaplan e Norton (1992).

O mapa estratégico representa a materialização da estratégia, retratando a dinâmica oferecida pelo BSC, a partir das relações de causa e efeito dos objetivos estratégicos (KAPLAN; NORTON, 1992). A Figura 1contempla uma ilustração das relações de causa e efeito (setas) dos objetivos estratégicos da GD. Esta ilustração mostra que "assegurar os recursos necessários voltados à aplicação dos planos de ação, projetos e programas estratégicos do setor" (objetivo estratégico da perspectiva financeira) contribui para o desenvolvimento profissional ao "incentivar capacitações e cursos para o aperfeiçoamento de pessoal da gestão documental e de seus usuários" (objetivo estratégico da perspectiva aprendizagem e crescimento), o que poderia auxiliar o desenvolvimento de processos da GD com qualidade superior (objetivos estratégicos da perspectiva processos internos), o que por sua vez, contribuiria para 
elevar o grau de satisfação dos usuários no que diz respeito à qualidade dos serviços/produtos da GD (objetivos estratégicos da perspectiva usuários). Além do exemplo da relação ilustrativa no mapa, várias outras relações podem ser definidas. A ideia é que se atente para todas as relações de causa e efeito possíveis.

Considerando os objetivos estratégicos associados a cada perspectiva, foram identificados os elementos constituintes das mesmas, a partir dos quais a influência da TI no desempenho da GD foi analisada. Estes elementos são apresentados no Quadro 2.

Quadro 2: Elementos de análise do desempenho da gestão documental

\begin{tabular}{|c|c|c|}
\hline \multicolumn{3}{|c|}{$\begin{array}{c}\text { Perspectiva Usuário } \\
\text { Como os serviços/produtos da gestão documental poderiam satisfazer seus usuários? }\end{array}$} \\
\hline \multirow{7}{*}{$\begin{array}{c}\text { Informação } \\
\text { Arquivística } \\
\text { (característica e } \\
\text { acesso) }\end{array}$} & Autenticidade & $\begin{array}{l}\text { Veracidade do conteúdo de um documento de arquivo em todas suas } \\
\text { idades (SOARES, 2012; RODRIGUES, 2006; RONDINELLI, 2005) }\end{array}$ \\
\hline & Integridade & $\begin{array}{l}\text { Completude do documento e integridade física (SOARES, } \\
\text { 2012;SANTOS; FLORES, 2015) }\end{array}$ \\
\hline & Precisão & $\begin{array}{l}\text { Exatidão das informações necessárias aos usuários (SOARES, 2012; } \\
\text { MORENO, 2008; NASCIMENTO; FLORES, 2008) }\end{array}$ \\
\hline & Essencialidade & $\begin{array}{l}\text { Preservação da informação arquivística pelo tempo necessário e } \\
\text { descarte da informação supérflua (SOARES, 2012; RODRIGUES, } \\
\text { 2006) }\end{array}$ \\
\hline & $\begin{array}{l}\text { Facilidade de } \\
\text { acesso }\end{array}$ & $\begin{array}{l}\text { Condições e meios eficazes de busca e recuperação da informação } \\
\text { arquivística (RIBEIRO, 1998; BAPTISTA; ESPANTOSO, 2008) }\end{array}$ \\
\hline & Tempo de acesso & $\begin{array}{l}\text { Tempo de recuperação da informação arquivística (RONCAGLIO; } \\
\text { SZVARÇA; BOJANOSKI, 2004; TEIXEIRA; SCHIEL;1997) }\end{array}$ \\
\hline & $\begin{array}{l}\text { Restrições de } \\
\text { acesso }\end{array}$ & $\begin{array}{l}\text { Medidas de restrições de acesso para garantir a confidencialidade dos } \\
\text { documentos (TONELLO; DA SILVA NUNES; PANARO, 2013) }\end{array}$ \\
\hline \multirow[t]{4}{*}{ Atendimento } & Confiabilidade & $\begin{array}{l}\text { Prestação dos serviços prometidos de forma confiável e precisa } \\
\text { (PARASURAMAN et al., 1985, 1988) }\end{array}$ \\
\hline & Segurança & $\begin{array}{l}\text { Conhecimento e capacidade de transmitir respostas com segurança } \\
\text { aos usuários (PARASURAMAN et al., 1985, 1988) }\end{array}$ \\
\hline & $\begin{array}{l}\text { Capacidade de } \\
\text { resposta }\end{array}$ & $\begin{array}{l}\text { Disposição em ajudar os usuários e fornecer o serviço com agilidade } \\
\text { (PARASURAMAN et al., 1985, 1988) }\end{array}$ \\
\hline & Empatia & $\begin{array}{l}\text { Capacidade de compreender e fornecer atenção às necessidade dos } \\
\text { usuários. (PARASURAMAN et al., 1985, 1988) }\end{array}$ \\
\hline \multirow[t]{2}{*}{ Conhecimento } & $\begin{array}{l}\text { Produtos/serviços } \\
\text { do arquivo }\end{array}$ & $\begin{array}{l}\text { Conhecimento pelos usuários das normas, serviços e produtos do } \\
\text { arquivo (GONÇALVES; SANTANA; JORENTE, 2015) }\end{array}$ \\
\hline & $\begin{array}{l}\text { Produtos/serviços } \\
\text { de TI }\end{array}$ & $\begin{array}{l}\text { Conhecimento pelos usuários das normas, serviços e produtos de TI } \\
\text { (ZANINELLI et al., 2016) }\end{array}$ \\
\hline \multicolumn{3}{|c|}{$\begin{array}{c}\text { Perspectiva Processos Internos } \\
\text { Em que processos da gestão documental devemos buscar o nível de excelência para satisfazermos as } \\
\text { necessidades dos usuários? }\end{array}$} \\
\hline \multirow{4}{*}{$\begin{array}{l}\text { Processos } \\
\text { Arquivísticos }\end{array}$} & $\begin{array}{l}\text { Produção } \\
\text { documental }\end{array}$ & $\begin{array}{l}\text { Processo padronizado de criação de documentos de arquivo em } \\
\text { ambiente convencional e digital (DORNELES; CORREAA, 2013; } \\
\text { BERNARDES; DELATORRE, 2008) }\end{array}$ \\
\hline & $\begin{array}{l}\text { Classificação } \\
\text { documental }\end{array}$ & $\begin{array}{l}\text { Processo de análise e de operações destinado a organizar e distribuir } \\
\text { a documentação de acordo com as diferentes estruturas, funções e } \\
\text { atividades da entidade produtora (RODRIGUES, 2006; SOUSA, } \\
\text { 2006; BERNARDES; DELATORRE, 2008) }\end{array}$ \\
\hline & $\begin{array}{l}\text { Avaliação } \\
\text { documental }\end{array}$ & $\begin{array}{l}\text { Processo de identificação de valores para os documentos e análise do } \\
\text { seu ciclo de vida visando estabelecer prazos de guarda e destinação } \\
\text { (INDOLFO, 2007; BERNARDES; DELATORRE, 2008) }\end{array}$ \\
\hline & Tramitação & Processo de estudo das instâncias de decisão, padronização e controle \\
\hline
\end{tabular}




\begin{tabular}{|c|c|c|c|}
\hline & \multicolumn{2}{|l|}{ documental } & $\begin{array}{l}\text { do fluxo documental (workflow) (INDOLFO, 2007; BERNARDES; } \\
\text { DELATORRE, 2008). }\end{array}$ \\
\hline $\begin{array}{l}\text { Processos de } \\
\text { Gestão }\end{array}$ & \multicolumn{2}{|l|}{$\begin{array}{l}\text { Planejamento } \\
\text { Estratégico }\end{array}$} & $\begin{array}{l}\text { Processo de planejamento da unidade de informação, das suas } \\
\text { operações e atividades, por meio da especificação de políticas, } \\
\text { objetivos, estratégias, desenvolvimento de ferramentas, } \\
\text { procedimentos e planos de trabalho (RAMOS, 1996) }\end{array}$ \\
\hline & \multicolumn{2}{|c|}{$\begin{array}{l}\text { Disseminação de } \\
\text { Serviços/Produtos }\end{array}$} & $\begin{array}{l}\text { Processo de divulgação dos serviços/produtos do arquivo disponíveis } \\
\text { aos usuários (PORTELLA; PEREZ, 2012; SOARES, 2012) }\end{array}$ \\
\hline & \multicolumn{2}{|c|}{$\begin{array}{l}\text { Avaliação da } \\
\text { satisfação do } \\
\text { usuário }\end{array}$} & $\begin{array}{l}\text { Processo de análise qualitativa e quantitativa da satisfação do usuário } \\
\text { com a prestação de serviços oferecida(SAMPAIO; REBELLO; } \\
\text { ZANI; BARREIROS; PRADO, CORDEIRO, VILLELA, 2004) }\end{array}$ \\
\hline \multicolumn{4}{|c|}{$\begin{array}{l}\text { Perspectiva Aprendizagem e Crescimento } \\
\text { capacidade de aprender, inovar e melhorar a gestão documental? }\end{array}$} \\
\hline \multicolumn{2}{|l|}{ Capacitação } & \multicolumn{2}{|c|}{$\begin{array}{l}\text { Capacitação de profissionais e usuários de acordo com suas necessidades de } \\
\text { conhecimento e desenvolvimento (PINTO; DEL CARPIO, 2011) }\end{array}$} \\
\hline \multicolumn{2}{|c|}{ Cultura de cooperação } & \multicolumn{2}{|c|}{$\begin{array}{l}\text { Cooperação como o contexto interativo em que as ações de um participante } \\
\text { favorecem o alcance do objetivo de outros (PALMIERI; BRANCO 2004); } \\
\text { trabalho em equipe e multidisciplinar (SOARES, 2003; MATOS, 2006) }\end{array}$} \\
\hline \multicolumn{2}{|l|}{ Tecnologias } & \multicolumn{2}{|r|}{$\begin{array}{l}\text { Adoção e implementação de tecnologias alinhadas às necessidade da gestão } \\
\text { documental (ANDRADE, 2017; ROCCO, 2013; RONDINELLI, 2005) }\end{array}$} \\
\hline \multicolumn{2}{|c|}{ Infraestrutura física } & \multicolumn{2}{|c|}{$\begin{array}{l}\text { Infraestrutura que a organização necessita desenvolver para suportar os } \\
\text { processos internos e assim satisfazer o usuário (MATOS, 2006). }\end{array}$} \\
\hline \multicolumn{4}{|c|}{$\begin{array}{c}\text { Perspectiva Financeira } \\
\text { Como deveríamos otimizar os recursos financeiros da gestão documental e consequentemente da } \\
\text { organização? }\end{array}$} \\
\hline \multicolumn{2}{|l|}{ Economicidade } & \multicolumn{2}{|c|}{ Racionalização dos gastos da instituição (NUINTIN, 2014) } \\
\hline \multicolumn{2}{|c|}{$\begin{array}{l}\text { Alinhamento dos recursos ao } \\
\text { planejamento estratégico }\end{array}$} & \multicolumn{2}{|c|}{$\begin{array}{l}\text { Integração e coerência entre o planejamento estratégico e recursos } \\
\text { (REZENDE, 2002; ALDAY, 2000) }\end{array}$} \\
\hline \multicolumn{2}{|c|}{$\begin{array}{l}\text { Otimização (qualidade dos } \\
\text { gastos, transparência) }\end{array}$} & \multicolumn{2}{|c|}{$\begin{array}{l}\text { Qualidade, custos versus benefícios, dos gastos (RIBEIRO, 2003) e } \\
\text { transparência em relação aos gastos (RAMOS; SCHABBACH, 2012). }\end{array}$} \\
\hline
\end{tabular}

Fonte: elaborado pelos autores (2018)

As perspectivas e os elementos de análise apresentados orientaram a elaboração do roteiro de entrevista aplicado em campo e a análise dos dados coletados.

\section{Percurso metodológico}

A pesquisa quanto à abordagem dos dados caracteriza-se como qualitativa (FLICK, 2009) e do tipo estudo de caso (YIN, 2001). O caso de estudo foi uma universidade pública do Brasil. A IES escolhida é uma das principais universidades da região sul do país, possuindo campi em cinco municípios do estado em que está localizada. A Universidade apresenta um quadro funcional composto por 3.174 técnicos administrativos e 2.170 docentes. A escolha desta universidade para a realização da pesquisa decorre da importância da instituição para o estado e para o país. Além disso, seu tamanho, fluxo documental intenso, uso de tecnologias da informação para a GD, bem como facilidade no acesso às informações, constituíram-se os critérios de escolha. 


\subsection{Participantes}

O conjunto de participantes da pesquisa foi composto por 9 profissionais: a) 3 gestores (de arquivo, de $\mathrm{TI}$ e de finanças) com tempo de trabalho na instituição superior a 20 anos, 1 deles com a titulação de mestrado e outros 2 de graduação; b) 3 arquivistas representantes dos arquivos setoriais da universidade, com tempo de trabalho de 8 anos e com titulação de pós-graduação em nível de especialização e, c) 3 usuários, com tempo de trabalho superior a 7 anos na instituição e com graduação. Para identificação dos usuários participantes foi efetuada uma entrevista não estruturada com os 3 arquivistas dos arquivos setoriais, a fim, de obter informações sobre quais servidores utilizam os serviços dos arquivos correntes, intermediários e permanentes, bem como, sobre a frequência de uso dos sistemas que auxiliam a GD.

Com o objetivo de manter o anonimato dos entrevistados, os mesmos foram referenciados no decorrer da seção de resultados da seguinte forma: gestor de TI, gestor financeiro, usuário $1,2,3$ e 4; arquivista 1, 2, 3 e 4, sendo o gestor de arquivo, um dos 4 arquivistas.

\subsection{Coleta e análise dos dados}

A coleta de informações do campo de estudo foi realizada por meio da técnica de entrevista semiestruturada, observação participante e pesquisa documental (TRIVINOS, 1987). Foram elaborados 4 roteiros de entrevistas considerando os participantes das entrevistas e as perspectivas de análise adotadas, conforme apresenta o Quadro 3.

Quadro 3 - Relação de participantes da pesquisa e perspectivas de análise

\begin{tabular}{|l|c|c|c|c|}
\hline \multirow{2}{*}{ Participante da entrevista } & \multicolumn{4}{|c|}{ Perspectivas de análise } \\
\hline Usuários (Roteiro 1) & Usuário & $\begin{array}{l}\text { Processos } \\
\text { Internos }\end{array}$ & $\begin{array}{l}\text { Aprendizagem e } \\
\text { Crescimento }\end{array}$ & Financeira \\
\hline Gestor de Arquivo e Arquivistas (Roteiro 2) & & & $\mathrm{X}$ & $\mathrm{X}$ \\
\hline Gestor de TI (Roteiro 3) & & $\mathrm{X}$ & $\mathrm{X}$ & $\mathrm{X}$ \\
\hline Gestor Financeiro (Roteiro 4) & & & & $\mathrm{X}$ \\
\hline
\end{tabular}

Fonte: Elaborado pelos autores (2018)

Os roteiros de entrevista foram elaborados com base na estrutura de análise delineada (seção 2) visando compreender a percepção dos participantes da pesquisa em relação aos elementos desta estrutura, bem como, a sua percepção quanto à influência da $\mathrm{TI}$ nestes elementos. As entrevistas foram realizadas no ambiente de trabalho dos participantes e gravadas com autorização dos mesmos. A cada entrevistado foi entregue e assinado um Termo de Consentimento Livre e Esclarecido, expondo os objetivos da pesquisa e os critérios éticos a ela pertinentes. 
Adicionalmente às entrevistas, foi utilizada a técnica de observação participante na qual o pesquisador interage e é, ao mesmo tempo, parte do contexto estudado (YIN, 2001). A técnica de pesquisa documental (TRIVINOS, 1987) foi utilizada para a coleta de dados secundários do contexto pesquisado. Foram utilizadas fontes que contribuíam com os objetivos da pesquisa como, por exemplo, site da instituição e outras publicações internas como jornais, relatórios e atas de reuniões.

O método de análise de dados utilizado nesta pesquisa foi a análise de conteúdo, conforme três etapas básicas (BARDIN, 2006): pré-análise, descrição analítica e interpretação inferencial. A pré-análise envolveu a transcrição das entrevistas e a organização das evidências coletadas a partir das diferentes técnicas de coleta de dados utilizadas. A descrição analítica foi realizada por meio da técnica de categorização. A forma de categorização utilizada foi mista. São definidas categorias preliminares, entretanto durante $o$ processo de análise podem emergir novas categorias, que podem ser acrescidas àquelas anteriormente definidas e indicar a necessidade de subdivisão, inclusão ou exclusão de categorias. As categorias preliminares foram definidas com base no referencial teórico e compõem a estrutura de análise abordada na seção 2.

\section{Resultados}

A instituição estudada conta com3 sistemas que apoiam a gestão documental, conforme identificado a partir dos depoimentos dos entrevistados: a) Solução Integrada para a Gestão Pública (SIGP); b) Sistema Acadêmico (SA);c) Sistema de Gerenciamento Eletrônico de Documentos (SGED). De forma geral, o uso destes sistemas apresenta contribuições e fragilidades à gestão de documentos na universidade, do ponto de vista dos participantes da pesquisa. O papel da $\mathrm{TI}$ em cada perspectiva teórica de desempenho da gestão documental é abordado a seguir.

\subsection{O papel da TI na perspectiva teórica "Usuários"}

A análise dos dados coletados a luz desta perspectiva permitiu identificar que os sistemas utilizados contribuem para garantir algumas das características intrínsecas aos documentos arquivísticos. A autenticidade da informação arquivística é reconhecida quando se trata de documentos físicos e digitais. Neste caso, a TI contribui com a autenticidade propiciando a certificação digital e o controle de conteúdo e de tramitação. Entretanto, com relação aos documentos digitalizados, o método de reprodução permite que os documentos sejam modificados, como ilustra este depoimento: “É de conhecimento geral que existe facilidade para a adulteração, modificação ou omissão de informações no SA, que permitem esse tipo de situação. Seria necessária uma 
modificação nos softwares para impossibilitar coisas desse tipo [...]" (Usuário 3)

Com relação à integridade da informação, a digitalização e o acesso remoto contribuem para que os documentos, físicos e digitais, permaneçam completos e em bom estado de conservação. O usuário 1 assim se manifesta:

Sabemos por onde os processos andaram e onde devemos procurar [...] O SGED faz com que as pessoas não fiquem manuseando os documentos. [...] Tenho acesso aos documentos no meu computador. O documento não precisa ficar de um lado para outro e não manuseio o documento original, ajudando na sua integridade.

A precisão da informação é reconhecida, porém, em alguns casos, quando erros são encontrados, são decorrentes de falha humana. Os sistemas em uso auxiliam na precisão da informação evitando a duplicidade e a adulteração de informações. Nas palavras do usuário 3 "existe a garantia da precisão a partir do momento que o documento não pode mais ser modificado e sim apenas visualizado". O acesso remoto aos documentos auxilia a essencialidade da informação, tornando-os mais facilmente acessível a quem deles precisa. Entretanto, a essencialidade é afetada pelo acúmulo desordenado de documentos físicos. A falta de mecanismos nos sistemas para eliminação de documentos desnecessários, como por exemplo, tabelas de temporalidade e descarte automático, interfere nesse elemento de análise. O usuário 2 sugere adaptação do SIGP para que se identifique a temporalidade e a destinação previstas na TTD no "instante da captura e do registro da informação".

Quanto ao acesso aos documentos digitais e digitalizados, de forma geral, os usuários entendem que suas rotinas de trabalho foram otimizadas com a implantação dos sistemas, propiciando rapidez e facilidade de acesso, como ilustra o depoimento do usuário 1: “O SIGP e o SGED me ajudam muito. Antes todos os documentos que eu necessitava estavam no Arquivo Central e isso atrasava muito o meu serviço. Hoje, raramente, necessito que documentos fora desses sistemas." Possibilidades de acesso remoto, simultâneo, a qualquer instante, em locais diferentes, são benefícios da TI, citados por usuários e arquivistas, que influenciam a facilidade e a rapidez de acesso à informação. Ao mesmo tempo, destacam que alguns sistemas utilizados apresentam também fragilidades que comprometem o acesso (facilidade e tempo), as quais são relacionadas: à validade legal de documentos digitalizados, às ferramentas de pesquisa e à instabilidade de um dos sistemas. O usuário 1 comenta: O SGED ajuda bastante, mas tem alguns documentos que eu necessito do original porque os documentos digitalizados não tem valor 
legal.[...]. No SGED acho ruim porque tenho que passar folha por folha até chegar ao documento que eu necessito. Isso acontece porque o sistema não tem campo de busca. (Usuário 1). O usuário 2 ilustra: "O SIGP trava quando várias pessoas fazem a mesma tarefa ao mesmo tempo" (Usuário 3).0 acesso aos documentos microfilmados é afetado tanto com relação à localização do setor onde estão disponíveis quanto com relação à falta de mecanismo de busca nas leitoras de microfilmes. No que se refere às medidas de restrições de acesso para garantir a confidencialidade dos documentos, são citadas como principais o uso de login e senha nos sistemas. Em relação ao SIGP, os usuários pesquisados entendem que os controles de acesso poderiam ser aprimorados, como comenta: "o SIGP não é seguro. As pessoas conseguem entrar no perfil de outro usuário e consultar todos os processos, solicitações e correspondências geradas pelo servidor nesse sistema. Esse campo de busca poderia ser melhorado e bloqueado para outros servidores" (Usuário 1).

Outro elemento analisado diz respeito ao papel da TI na prestação dos serviços aos usuários pelos servidores do Arquivo e pelos servidores de $\mathrm{Tl}$. Os usuários entendem que uma das contribuições da TI quanto a este aspecto é decorrente da ampliação das possibilidades de canais de atendimento, como por exemplo, e-mails e sistemas destinados à solicitação dos serviços (portal de chamada), bem como da possibilidade de realização do serviço a distância, o que contribui para a confiabilidade e capacidade de resposta: "Eu acho que a TI auxilia muito a prestação de serviços pela [área de $\mathrm{TI}$ ], pois é necessário preencher um formulário para que o atendimento seja registrado", diz o usuário 1 . O registro da ocorrência também é importante para o aperfeiçoamento do atendimento, conforme cita o Usuário 3. De acordo com o mesmo, a TI contribui porque agiliza e deixa registrado o fato, servindo de prova e de exemplo para a melhoria no atendimento e solução de problemas futuros. Os próprios canais contribuem para que mudanças e problemas nos serviços prestados sejam comunicados, o que ocorre comumente por email ou telefone (voip). Também em relação à área de $\mathrm{TI}$, a possibilidade de realização do serviço a distância denota contribuições da $\mathrm{TI}$ ao atendimento, como ressalta o usuário 1: “A TI utilizada contribui no atendimento dos servidores da $\mathrm{TI}$ porque os serviços podem ser realizados remotamente se o seu computador estiver sendo gerenciado por eles." Na visão do usuário 2, a existência de diferentes canais de atendimento possibilitados pela TI também demonstra interesse e atenção às necessidades dos usuários (empatia): "Você pode ser atendido por email, por telefone e isso mostra um interesse maior em resolver as necessidades do usuário", mas este mesmo usuário entende que "isso não auxilia na boa vontade deles". De forma similar, os Usuários 1 e 3 afirmam que a TI não contribui para que 
os servidores de arquivo e os servidores de $\mathrm{TI}$ compreendam as necessidades e demonstrem boa vontade para atender as solicitações do usuário.

Ainda é entendido que a agilidade (capacidade de resposta) na prestação de serviço ocorre por meio do uso da TI pelos próprios setores responsáveis pelo atendimento aos usuários: O usuário 1 explica: “Quando solicito um processo ao arquivo, percebo que eles consultam uma tabela no computador para encontrar a caixa que ele está e isso torna o trabalho mais rápido e eficiente". Mesmo considerando as contribuições da TI citadas à prestação de serviços aos usuários, os usuários e arquivistas entendem que o atendimento dos profissionais de TI comumente é realizado com lentidão e tem a expectativa de retorno mais ágil daquele setor.

Quanto à influência da $\mathrm{TI}$ no conhecimento dos servidores e na sua capacidade de transmitir respostas com segurança, os usuários 1 e 3 consideram que esta é uma questão que depende mais do próprio servidor, do seu interesse em buscar aperfeiçoamento constante, do que propriamente da TI. Como diz o usuário 3: “A TI contribui sempre, mas cabe aos servidores buscar o conhecimento e se manter atualizado sempre". O usuário 2 entende que a TI contribui com estes aspectos por meio da possibilidade de cursos de aperfeiçoamento e a distância.

O conhecimento sobre as normas, serviços e produtos oferecidos pelos servidores de TI e pelos servidores do Arquivo Central, em parte são obtidos por meio do auxílio da $\mathrm{TI}$, em especial é feito referência a um dos sistemas utilizados (SIGP) e ao website. Porém, os usuários evidenciam a necessidade de exploração mais completa da TI para esta finalidade. Nas palavras do usuário 2: “Poderiam enviar e-mails e colocar na página da universidade também. Acho que poderia ser mais explorado. Eu não vejo nada no site da [área de $\mathrm{TI}$ ] sobre os serviços, também não recebo email. Às vezes acho que eles não querem mesmo que a gente saiba. Acho que poderia ter um jornal virtual com todos os serviços prestados pelos setores da universidade." Os usuários ainda mencionam a necessidade de aprimorar as capacitações voltadas aos serviços oferecidos pelo Arquivo Central e pelo setor de $\mathrm{TI}$.

\subsection{O papel da TI na perspectiva teórica "Processos I nternos"}

Constatou-se que a TI não é utilizada para o planejamento estratégico da gestão documental, mas, fundamentalmente, para disponibilização do acervo. A Arquivista 4 entende que a TI "poderia contribuir na divulgação do planejamento da GD" (Arquivista 4).

No que se refere à produção documental, a TI auxilia na padronização documental gerada digitalmente, a partir de formulários 
padrão implementados no sistema, bem como no controle da geração destes documentos e no fornecimento de indicadores de produção. Os sistemas e softwares adotados "padronizam a documentação gerada nas diversas áreas de atuação da instituição" (Arquivista 1), ou seja, "os documentos gerados seguem o mesmo padrão" (Arquivista 4). Entretanto, a TI não é utilizada para padronização e controle da produção de documentos físicos. A Arquivista 4 menciona que para os documentos físicos "não existe controle algum".

Outro ponto observado pelos Arquivistas1, 2 e 3 é sobre um dos requisitos do Arquivo Nacional (2011), relacionado à classificação documental, no qual o documento deveria nascer já classificado e englobar todo o seu ciclo de vida com a temporalidade já definida. Porém, os sistemas não apresentam a funcionalidade para classificação documental, ou seja, o plano de classificação não está implementado nos sistema e o código de classificação do documento não é atribuído ao documento digital/digitalizado. Entende-se necessário “Estabelecer que o documento criado em formato digital tenha como uma de suas obrigatoriedades no seu momento de produção a sua classificação com base nas normativas do Arquivo Central da instituição". (Arquivista 2).

De forma similar, a TI não vem contribuindo para a avaliação documental dada a ausência de funcionalidade nos sistemas que permita a avaliação documental. A tabela de temporalidade não está implementada no sistema e o prazo de guarda não é atribuído ao documento digital/digitalizado. Como explica a Arquivista 3, "não existe campo para classificar e atribuir prazo de guarda". Conforme preconiza o Arquivo Nacional (2011), o sistema deve identificar a temporalidade e destinação previstas na TTD da instituição no instante da captura e do registro da informação. Já no caso dos documentos no suporte físico, “[...] a TI auxilia só na divulgação da Tabela de Temporalidade [...]"(Arquivista 4), favorecendo a sua divulgação e acesso.

Uma questão unânime das entrevistas com os arquivistas e o Gestor de TI foi quanto ao apoio da TI no controle da tramitação dos documentos eletrônicos e físicos, ao possibilitar o registro do trâmite documental, a sua visualização e rastreamento, por meio de campos de busca, a realização de auditoria, como ilustra o relato do Gestor de TI: “É possível ter acesso a toda tramitação dos documentos. Quando o documento é digital toda sua tramitação fica registrada no sistema, desde a sua criação até o arquivamento. Quando o documento é físico toda sua tramitação também ocorre no sistema. O documento físico tramita junto e os setores da universidade não recebem o documento se não tiverem com o registro correto no SIGP.“

Sobre a disseminação de normas, serviços e produtos do setor de arquivo, os Arquivistas (1, 2 e 4) detalham que o Arquivo Central utiliza 
website do setor, email e sistemas em uso. A TI não é utilizada pelos Arquivos Setoriais com o objetivo de disseminação de informações sobre o setor, mas os responsáveis estão realizando reformulações nos sites dos departamentos para atenderem essa demanda. Tal preocupação é extraída de dois Arquivistas: "Estamos elaborando o site com formulários para servidores e alunos solicitarem serviços e produtos", diz o Arquivista 3. No caso do setor de $\mathrm{TI}$, a divulgação dos seus produtos e serviços é apoiada pela $\mathrm{TI}$ de várias formas como website, sistema de gestão documental e feeds de notícias contribuem para divulgação das normas, serviços e produtos da área de $\mathrm{TI}$ como aborda o Gestor de $\mathrm{Tl}$ : "Utilizamos o Solar, site do [setor] e da universidade para divulgar novos serviços e produtos e o site da capacitação para divulgação de cursos. É possível também baixar o Thunderbird e receber as notícias da página da [área de $\mathrm{TI}$ ] direto de seu feed."

Todas as avaliações de satisfação dos usuários quanto aos serviços prestados no Arquivo Central e Arquivo Setorial são realizadas informalmente, ou seja, não há a realização formal de avaliações. Contudo, os arquivistas reconhecem a contribuição em potencial da TI para avaliação da satisfação dos usuários, apesar de não fazerem uso da mesma com este objetivo. O canal de atendimento da área de $\mathrm{TI}$ possibilita inserir reclamações ou sugestões. O gestor de $\mathrm{TI}$ explica: “O portal de chamados disponibilizado pela [área de $\mathrm{TI}$ ] possibilita que o usuário avalie o serviço prestado e deixe sugestões e reclamações" (Gestor de TI). Avaliar formalmente a satisfação do usuário possibilita aprimorar os serviços e produtos oferecidos tanto pelos Arquivos Central e Setorial quanto pela área de TI da universidade.

\subsection{O papel da TI na perspectiva teórica “Aprendizagem e Crescimento"}

Nesta perspectiva, observam-se relatos diferentes quanto ao apoio da TI à capacitação decorrente da sua experiência na instituição. Para os Usuários ( 1 e 3), a TI não foi utilizada em nenhuma capacitação cursada dentro da universidade. O Usuário 2 utilizou a TI, contudo a maneira como foi empregada dificultou o curso, como descreve: "Eu achei muito cansativo e muito difícil para quem não tem muito domínio de sistemas. Eu desisti desse curso porque não consegui acompanhar. Os vídeos poderiam ser mais explicativos." Os Arquivistas entrevistados afirmam que não existem cursos voltados especificamente para o aperfeiçoamento desses profissionais da informação. Na visão dos Arquivistas (1, 2 e 4), a universidade deveria oferecer cursos voltados para o aperfeiçoamento dos arquivistas virtualmente ou presencialmente. Somente o Arquivista 3 utilizou a TI, plataforma de ensino a distância da universidade para realização de capacitação, não direcionada especificamente para sua área, 
destacando o acesso remoto um facilitador para conclusão do curso. 0 gestor de $\mathrm{Tl}$ observa que para o aperfeiçoamento dos profissionais de $\mathrm{TI}$ e usuários, vários cursos de capacitação de sistemas e programas da instituição são oferecidos na modalidade a distância, como explica: "Vários cursos oferecidos são virtuais na plataforma moodle com vídeos explicativos e tutores online".

Observa-se também nas entrevistas que a TI não é utilizada como apoio à cultura de cooperação entre os profissionais da informação. Os usuários e arquivistas apontaram que a TI em uso não contribui para o compartilhamento da informação e conhecimento entre os profissionais de GD. Para eles, a cooperação entre as áreas está relacionada à cultura institucional e à conscientização dos servidores. "Falta conscientização da importância do trabalho integrado", diz o Usuário 2. De forma similar, o Arquivista 3 manifesta: "Falta conscientização de todos profissionais que realizam a gestão documental na universidade" (Arquivista 3). No caso do setor de $\mathrm{TI}$, o seu gestor argumenta que os sistemas existentes contribuem para que os servidores de $\mathrm{TI}$ trabalhem juntos e simultaneamente em vários sistemas da universidade. Para ele, o SIGP promove "o trabalho colaborativo entre as áreas porque tem um ambiente unificado e padronizado".

Em relação às tecnologias de informação utilizadas, elemento integrante da perspectiva aprendizagem e crescimento, os entrevistados foram questionados sobre os pontos fortes e fragilidades das mesmas, enquanto suporte às atividades organizacionais. Como pontos fortes foram citados: a automatização da tramitação documental; controle/segurança (protocolo rastreável, facilidade em auditorias), digitalização e disponibilização remota dos documentos, acesso rápido às informações acadêmicas, redução da burocracia, gestão integrada, aumento da transparência, diminuição da informalidade. O usuário 1 assim se manifesta: "Eu consigo consultar a tramitação, abrir processos e solicitações dos documentos da minha mesa". O gestor de TI assim discorre sobre os benefícios dos sistemas em uso: "A integração entre os módulos de gestão de materiais e almoxarifado, gestão de compras e licitações, gestão patrimonial e processos administrativos, diminuição da burocracia e uso de papel, rapidez, protocolo rastreável, armazenamento em meio digital, maior facilidade em auditorias, diminuição da informalidade e aumento da transparência (Gestor de TI)."

Quanto às fragilidades foram destacados: problemas técnicos e instabilidade do SIGP (expressões como "é muito lento", "é muito devagar" "sempre trava", "trava toda hora", "vive fora do ar ou em manutenção" foram utilizadas por usuários e arquivistas); pouca usabilidade ("sistema de interface confusa" "sistema chato", "às vezes não encontro um atalho para realizar alguma atividade" foram algumas das 
expressões usadas); falta de alinhamento à realidade institucional; pouca flexibilidade; falta de mecanismo de validade legal dos documentos digitalizados; deficiências e/ou ausência de mecanismos (campos) de busca dos documentos digitalizados. O usuário 3 assim se manifesta quanto ao SA: "Desatualizados, os sistemas tanto da graduação quanto da pós. Não se fala em melhorias e tampouco se busca atualizações. O Sistema Acadêmico não possui validade legal, portanto os documentos em papel não podem ser eliminados" (Usuário 3). O depoimento do Gestor de TI ilustra pontos fracos do SIGP: “[...] instabilidade, burocracia no sentido das diversas etapas necessárias para o cadastro de um procedimento, constantes problemas técnicos, mal adequação à realidade institucional, sistema não desenvolvido exclusivamente para a universidade, ou seja, a instituição precisou se adaptar ao software, preço, aceitação, código fonte, e pouca flexibilidade."

Outro ponto destacado nas entrevistas relaciona-se aos hardwares (computadores, impressoras, scanners, rede física). Termos como "velhos", “defasados", "antigos", “quebrados", "sempre em manutenção" foram utilizados por usuários e arquivistas para referenciar o estado dos equipamentos. O Gestor de TI argumenta que tem conhecimento quanto às condições dos hardwares, porém remete este fato à falta de recursos financeiros, como declara: "a universidade está com um grande problema de recursos financeiros e isso remete ao controle de gastos".

\subsection{O papel da TI na perspectiva teórica "Financeira"}

No entendimento de todos os Arquivistas, quanto ao quesito economicidade, os sistemas geraram economia de tempo, trabalho e de recursos financeiros. "A aquisição de sistemas de fora da universidade proporciona a utilização imediata dos mesmos, resultando em grandes benefícios, inclusive econômicos", ressalta a Arquivista 2. "Otimiza o tempo e o dinheiro, facilita o trabalho.", declara a Arquivista 3. Entretanto, os Gestores de TI e Financeiro argumentam que não houve economia financeira com a implantação do SIGP. Documentos fornecidos pelo Almoxarifado Central também comprovam que o consumo de papel aumentou depois da implantação do sistema. Leia-se o depoimento: "O principal objetivo da universidade era gerar economia de papel e isso não aconteceu. O consumo de papel só tem aumentado a cada ano" (Gestor Financeiro). Observa-se que a implantação dos sistemas automatizou as atividades gerando economia de tempo e evitando o retrabalho dos servidores, porém ao contrário do esperado, ocorreu o aumento do consumo do papel e não há evidências tangíveis de economia financeira direta.

No que se refere ao alinhamento dos recursos destinados à gestão documental ao planejado, o Gestor de TI e o Gestor Financeiro fazem 
referência ao Sistema Integrado de Administração Financeira (SIAFI), sistema online do governo federal, que possibilita o alinhamento entre o orçamento e o planejamento da universidade. Porém, o uso do SIAF não se aplica especificamente à Gestão Documental, uma vez que estes gestores desconhecem a existência de recursos orçamentários específicos à mesma. O Gestor Financeiro explica que "Não existe recursos destinados à gestão documental, mas o SIAFI poderia contribuir se tivesse parte do orçamento destinado à gestão documental".

Quanto à otimização (qualidade dos gastos e transparência), os Arquivistas entrevistados entendem ser necessário não apenas aumentar os recursos financeiros destinados à GD, mas também melhorar a qualidade dos gastos da universidade voltados a esta gestão. O Gestor de TI e o Gestor Financeiro entendem que as funcionalidades do SIAFI auxiliam na otimização dos recursos gerais da universidade e permite comparações com os gastos das outras universidades, uma vez que o sistema é contempla todo o território nacional. “Dentro do sistema é possível adequar e controlar o orçamento institucional, otimizando a utilização dos recursos" explica o Gestor Financeiro. Também, o Gestor de $\mathrm{TI}$ e o Gestor Financeiro mostram, em seus depoimentos o apoio da $\mathrm{TI}$, mais especificamente do SIAF, para a transparência dos gastos na universidade, pois o sistema apresenta relatórios detalhados dos gastos públicos e publicados em forma de relatórios no site. O seguinte relato ilustra: Toda a prestação de contas fica registrada e todas as pessoas que tenham interesse podem consultar pelo SIAFI (Gestor de TI).Os arquivistas fazem referência ao "Portal da Transparência", que na sua visão auxilia na transparência em relação à destinação e aplicação dos recursos financeiros, como descreve o Arquivista 2: “Hoje temos acesso aos gastos da universidade pelo Portal da Transparência e o departamento financeiro sempre tem que prestar contas de seus gastos." (Arquivista 2). Segundo o site do Governo Federal, os dados disponibilizados no Portal da Transparência são obtidos por meio de relatórios do SIAFI.

A análise da influência da TI no desempenho da gestão documental da universidade também possibilitou evidenciar um conjunto de relações entre as perspectivas de desempenho. Exemplos destas relações são apresentados na próxima seção.

\subsection{0 papel da TI na relação entre as perspectivas de desempenho da gestão documental}

A relação causa/efeito preconizado pelo BSC também aparece quando se analisa a percepção dos entrevistados quanto ao papel da TI no desempenho da gestão documental. Por exemplo, o Arquivista 1 quando diz que "a equipe do Arquivo Central elaborou vocabulário controlado para ser adotado pela área de TI na fase de implantação do sistema SIGP. A 
área de TI não adotou o instrumento", mostra a relação entre a fragilidade no elemento cultura de cooperação (perspectiva aprendizagem e crescimento) e a sua influência no apoio da $\mathrm{TI}$ à processos da gestão documental (perspectiva processos internos), assim como, respectivamente na perspectiva usuários.

Outro exemplo de relação de causa e efeito pode ser evidenciado analisando-se os relatos do Usuário 3: "documentos microfilmados não foram devidamente avaliados na época em que a instituição realizava esse tipo de atividade" e "o usuário deve se deslocar até lá para ter acesso às informações porque o [...]é o único setor da universidade que tem leitora de microfilme". Este relato mostra a relação das perspectivas dos processos internos (avaliação documental), aprendizagem e crescimento (infraestrutura física) e suas influências no acesso à informação arquivística (perspectiva usuário).

A relação causa/efeito entre as perspectivas usuários, processos internos e, aprendizagem e crescimento também podem ser observados a partir da análise das entrevistas. Por exemplo, o Arquivista 2 quando diz "Você pode ser atendido por email, por telefone e isso mostra um interesse maior em resolver as necessidades do usuário" mostra a relação entre a tecnologia (perspectiva aprendizagem e crescimento) e a sua influência no atendimento (perspectiva usuários), garantindo assim, a satisfação do usuários (perspectiva usuários).

A análise das percepções sobre 0 desempenho da gestão documental e da contribuição da TI nas perspectivas analisadas, assim como a evidenciação da relação entre estas perspectivas permitiu identificar que a forma como a TI é aplicada nos elementos de uma perspectiva pode apresentar efeitos nas demais, bem como, que o apoio da $\mathrm{TI}$ ao desempenho da gestão documental não depende somente de questões tecnológicas.

\section{Considerações finais}

Os resultados desta pesquisa mostram que o uso da TI apresenta potencial para contribuir com todas as perspectivas de desempenho da GD: satisfação dos usuários; qualidade dos processos documentais, capacidade de aprender, inovar e melhorar a GD e otimização dos recursos financeiros da GD e da universidade como um todo. Considerando este potencial, a $\mathrm{TI}$ em uso na universidade pesquisada, vem contribuindo parcialmente e ainda timidamente com o desempenho da GD, da forma como desempenho é compreendido e analisado neste estudo. Este fato repercute diretamente na perspectiva usuários e nos seus elementos integrantes, ou seja, na garantia das características da informação arquivística, do acesso rápido e seguro à informação, na 
qualidade do atendimento e no conhecimento dos usuários em relação aos serviços/produtos da gestão documental.

A estrutura de análise utilizada permitiu identificar que a maximização do apoio da $\mathrm{TI}$ ao desempenho da gestão documental depende de questões de outras naturezas e não apenas daquelas de ordem tecnológica. Na universidade pesquisada, estas questões estão relacionadas, por exemplo, à: a) necessidade de melhorias em alguns processos da gestão documental, como planejamento estratégico da área, sua disseminação e aplicação; e avaliação da satisfação dos usuários (perspectiva processos internos); b) aplicação da TI em uso a alguns destes processos, principalmente, à classificação e à avaliação documental; (perspectivas processos internos e aprendizagem e crescimento); (c) à necessidade de aprimoramentos quanto à capacitação e conscientização dos usuários (perspectiva aprendizagem e crescimento) (d) à carência de realização de um trabalho mais integrado entre todos os profissionais cujos setores que atuam afetam a GD, seja em tempo de planejamento da GD e da definição de requisitos para a adoção de sistemas, seja em tempo de uso dos sistemas (perspectiva aprendizagem e crescimento), (e) previsão de recursos financeiros alinhados ao planejamento e às necessidades da GD (perspectiva financeira).

Além das contribuições advindas dos resultados desta pesquisa, outra contribuição acadêmica relaciona-se ao desenvolvimento de uma estrutura conceitual de avaliação de desempenho da gestão documental para uma instituição de ensino superior pública, a partir de conhecimentos teóricos interdisciplinares das áreas de administração, arquivologia e tecnologia da informação. A aplicação desta estrutura à universidade pesquisada evidenciou seu potencial para qualitativamente compreender o papel da TI no desempenho da GD e identificar oportunidades de melhorias naquele contexto. Esta estrutura poderá subsidiar gestores de outras instituições de ensino superior na análise da contribuição da TI em uso ao desempenho da GD e na identificação de ações que possam maximizar esta contribuição. Além disso, a estrutura pode colaborar para uma gestão da TI mais alinhada e integrada à gestão documental.

Como estudos futuros recomenda-se o aprimoramento da estrutura conceitual de desempenho da gestão documental proposta a partir de investigações qualitativas e quantitativas sobre o tema, em outros contextos empíricos.

\section{Referências}

ALBERTIN, A. L.; ALBERTIN, R. M. M. Benefícios do uso de tecnologia de informação para o desempenho empresarial, RAP, Rio de Janeiro, v. 42, n. 2, p. 275-302, mar. 2008.Disponível em: https://www.researchgate.net/profile/Alberto_Albertin/publication/250 
991056 Beneficios do uso de tecnologia de informacao para o desem penho empresarial/links/55c8d93d08aebc967 df90532/Beneficios- do-usode-tecnologia-de-informacao-para-o-desempenho-empresarial.pdf. Acesso em: 23 out. 2016.

ALDAY, H. E. C. O. Planejamento Estratégico dentro do Conceito de Administração Estratégica, Revista FAE, Curitiba, v. 3, n. 2, 2000.

Disponível em: file:///C:/Users/Terezinha/Downloads/505-1292-1-SM.pdf. Acesso em: 14 maio 2016.

ANDRADE, F. H. A. Os desafios na implementação do sistema de arquivos na Universidade Federal de Juiz de Fora: o caso da CAP/PROGEPE. 2017. 166 f. Dissertação (Mestrado profissional em Gestão e Avaliação da Educação Pública)-Faculdade de Educação, Universidade Federal de J uiz de Fora, Juiz de Fora, 2017. Disponível em:

http://repositorio.ufjf. br: 8080/jspui/bitstream/ufjf/6032/1/felipehenriquea Ivesdeandrade.pdf..Acesso em: 15 dez. 2017.

ARQUIVO NACIONAL (2011). E-Arq: modelo de requisitos para sistemas informatizados de Gestão Arquivística de Documentos. Conselho Nacional de Arquivo. Rio de Janeiro, 2011. 133 p. Disponível em:

http://www.siga.arquivonacional.gov. br/images/publicacoes/e-arq.pdf. Acesso em: 06 mar. 2016.

BAHIA, E.M. S.; BLATTMANN, U. Conviver o momento da transição: Universidade Federal de Santa Catarina-sem papel. Biblos: Revista do Instituto de Ciências Humanas e da Informação, v. 25, n.2, p. 57-73, jul. 2011. Disponível em: https://periodicos.furg. br/biblos/article/view/2683/1503. Acesso em: 17 out. 2016

BARDIN, L. Análise de conteúdo.Lisboa: Edições 70. (Obra original publicada em 1977), 2006.

BAPTISTA, S. G. O.; ESPANTOSO, J. J. P. O.O trabalho do bibliotecário e outros profissionais da informação na organização e projeto de espaços de informação digitais. DataGramaZero, v. 9, n. 2, p. 1-18, 2008. Disponível em: https://www.brapci.inf.br/index.php/res/v/26292. Acesso em: 18 ago. 2016.

BERNARDES, I. P.; DELATORRE, H. Gestão documental aplicada. São Paulo: Arquivo Público do Estado de São Paulo,2008. 54 p.

BRIAND, B. et al.Indicateurs de performance des services documentaires; l'expérience d'ungroupe de professionnels de l'information.

Documentaliste - Sciences de l'Information, Paris, v. 39, n. 1/2, p. 26-33, 
2002.Disponível em: https://www.cairn.info/revue-documentalistesciences-de-l-information-2002-1-page-26.htm\#. Acesso em: 10 jan.2017.

CARPES, F. S.; CASTANHO, D. M. As políticas públicas e a gestão documental nas Universidades Federais do Rio Grande do Sul, Revista Sociais \& Humanas, Santa Maria, v. 27, n. 2, p. 72-90, mai. 2014. Disponível em: https://periodicos.ufsm.br/sociaisehumanas/article/view/4926/pdf . Acesso em: 03 de nov. 2016.

CISCATO, M. F.; CARGNELUTTI, L. S.; GARCIA, O. M. C.; CARPES, F. S.Arquivo universitário: implantação de políticas de gestão de documentos no gabinete do vice-reitor da UFSM, Biblos: Revista do Instituto de Ciências Humanas e da Informação, [s.I], v. 25, n. 2, p. 9-29, jul. 2011.Disponível em: http://www.repositorio.furg. br/handle/1/4104. Acesso em: 06 nov. 2016.

COSTA, J. H. L.; SILVA, A. K. A. Gestão de arquivo na visão dos usuários internos: qualidade dos serviços do Arquivo do Centro de Ciências Humanas, Letras e Artes/UFPB, Archeion Online, João Pessoa, v. 3, n. 1, p. 4-24, jan. 2015. Disponível em: https://repositorio.ufpb.br/jspui/handle/123456789/1245. Acesso em: 17 ago. 2016.

DORNELES, S. L.; CORRÊA, R. F. Gestão de documentos digitais em aplicações de certificação digital, Informação Arquivística, v. 2, n. 2, p.331, jul./dez. 2013. Disponível em: http://www.aaerj.org.br/ojs/index.php/informacaoarquivistica/article/view L28. Acesso em: 24 out. 2016

FELIX, A.; SILVA, E. A gestão documental como suporte ao governo eletrônico: caso da Secretaria de Estado da Saúde de Santa Catarina (SES/SC), Revista Democracia Digital e Governo Eletrônico, [s.I.], v. 2, p. 4, 2010.Disponível em: http://buscalegis.ufsc. br/revistas/index.php/observatoriodoegov/article/vi ew/19. Acesso em: 18 nov. 2016.

FLICK, U. Introdução à pesquisa qualitativa. 3. ed. São Paulo: Artmed, 2009.

GERONIMO, M. B. O arquivo universitário e as suas diretrizes: um estudo de caso do sistema de arquivo da Unicamp (SIARQ). 2014. $154 \mathrm{f}$. Dissertação (Mestrado em Ciência da Informação)-Faculdade de Filosofia e Ciências, Universidade Estadual Paulista, 2014. Disponível em: https://www. marilia.unesp.br/Home/Pos- 
Graduacao/Cienciadal nformacao/Dissertacoes/geronimo_mb me_mar.pdf

- Acesso em: 15 jan. 2017.

GONÇALVES, P. R. V. A.; SANTANA, R. C. G.; J ORENTE, M. J . V.. Privacidade do usuário na atividade de busca: o caso do Arquivo Público do Estado de São Paulo, Perspectivas em Ciência da Informação, v.20, n.3, p.137-151, jul./set. 2015.Disponível em: http: //www.scielo.br/scielo.php?script=sci_arttext\&pid=S141399362015000300137\&lng=pt\&tlng=pt. Acesso em: 24 jun. 2016.

INDOLFO, A. C. Gestão de Documentos: uma renovação epistemológica no universo da arquivologia,Arquivistica. net, Rio de Janeiro, v. 3, n. 2, p. 28-60, jul. 2007. Disponível em: https://www.brapci.inf.br/index.php/article/view/0000005190. Acesso em: 19 jul. 2016.

KAPLAN, R. S.; NORTON, D. P. The Balanced Scorecard: measures that drive performance, Harvard Business Review, [S.I.], v. 70, n. 1, p. 71-79, jan. 1992. Disponível em: https://steinbeis-

bi.de/images/artikel/hbr 1992.pdf. Acesso em: 07 fev. 2016.

MATOS, L. F.A utilização do Balanced Scorecard para monitorar o desempenho de um Hospital.2006. 116 f. Dissertação(Mestrado em Sistemas de Informação). Escola de Engenharia - Universidade do Minho, Guimarães, 2006. Disponível em:

http://repositorium.sdum.uminho.pt/handle/1822/7185. Acesso em: 22 mar. 2016.

MEIRELES, M. R. G.; ROCHA, D. M.; CENDÓN, B. V. Avaliação da implantação de uma tecnologia para gerenciamento de documentos como ferramenta do processo de gestão da informação. Revista ACB: biblioteconomia em Santa Catarina, v. 17, n. 2, p. 332-348,2012. Disponível em: https://www.brapci.inf.br/index.php/res/v/76288. Acesso em: 09 mai. 2016.

MORENO, N. A. Gestão documental ou gestão de documentos: trajetória histórica. In: BARTALO, L. MORENO, M. A. (Org.). Gestão em Arquivologia: abordagens múltiplas. Londrina: EDUEL, 2008. P.71-88. Cap. 3.

NASCIMENTO, M. A.; FLORES, D.A gestão da informação arquivística como subsídio ao alcance e à manutenção da qualidade. Arquivística.net, Rio de janeiro, v. 3, n. 2, p. 62-77, jul. 2008. Disponível em: https://www.brapci.inf.br/index.php/article/view/0000005191/\%205a2c4 45c64f3f290fbc29d03beb6bc0f. Acesso em: 07 nov. 2016. 
NUINTIN, A. A. Eficiência da aplicação de recursos públicos nas universidades federais.2014. 169 f. Tese (Doutorado).: il. Lavras: UFLA, 2014. Disponível em:

https://anaiscbc.emnuvens.com.br/anais/article/view/3783Acesso em: 07 nov. 2016.

PALMIERI, M. W. A.; BRANCO, A. U. Cooperação, competição e individualismo em uma perspectiva sócio-cultural construtivista, Psicologia: reflexão e crítica, v. 17, n. 2, p. 189-198, 2004. Disponível em: http://www.scielo.br/pdf/prc/v17n2/22471.pdf. Acesso em: 10 nov. 2016.

PARASURAMAN, A.; ZEITHAML, V. A.; BERRY, L.L.A conceptual model of service quality and its implications for future research. Journal of Marketing,v. 49, p. 41-50, 1985.Disponívelem:

https://edisciplinas.usp.br/pluginfile.php/2491773/mod resource/content/ $1 /$ Conceptual $\% 20$ Model $\% 20$ of $\% 2$ S Service $\% 20$ Quality $\% 20$ and $\% 201$ ts $\% 20$ Implications\%20for\%20Future\%20Research.pdfAcesso em: 29 nov. 2016.

. SERVQUAL: A multiple-item scale for measuring consumer perceptions of service quality. J ournal of Retailing, v. 64, n. 1, p. 12-40, 1988. Disponível em:

https://www.researchgate.net/profile/Valarie Zeithaml/publication/22508 3802 SERVQUAL A multiple-

Item Scale for measuring consumer perceptions of service quality/lin ks/5429a4540cf27e39fa8e6531/SERVQUAL-A-multiple-I tem-Scale-formeasuring-consumer-perceptions-of-service-quality.pdf. Acesso em: 29 nov. 2016.

PORTELA, V. DE P.; PEREZ, C. B. Práticas comunicacionais: difusão no Arquivo Público do Estado do Rio Grande do Sul nos diferentes meios de comunicação online. Em Questão, v. 18, n. 1, 2012. Disponível em: https://seer.ufrgs.br/EmQuestao/article/view/22930. Acesso em: 11 nov. 2016.

PINTO, S. R. R.; DEL CARPIO, G. R. A. Me. Fatores críticos para a implantação do balanced scorecard: a visão de consultores organizacionais, Revista de Administração e Contabilidade da Unisinos, p. 311-324, 2011. Disponível em:

http://www.spell.org.br/documentos/ver/7087/fatores-criticos-para-aimplantacao-do-balanced-scorecard--a-visao-de-consultoresorganizacionais. Acesso em:07 fev. 2016.

POMBAL, B. M. O. Gestão da eficiência em serviços de documentação e informação. Dissertação. (Mestrado)-FEUP, Porto, 2009.Disponível em:https://repositorio- 
aberto.up.pt/bitstream/10216/19295/2/25690.pdf. Acesso em: 01 set. 2016.

RAMOS, P A. B.A gestão na organização de unidades de informação. Ciência da informação, v. 25, n. 1 p.15-25, 1996. Disponível em: http://revista.ibict.br/ciinf/article/view/671/680. Acesso em: 01 set. 2016.

RAMOS, M. P.; SCHABBACH, L. M. O estado da arte da avaliação de políticas públicas: conceituação e exemplos de avaliação no Brasil, Revista de Administração Pública, v. 46, n. 5 p. 1272-1294, set. 2012. Disponível em: http://bibliotecadigital.fgv.br/ojs/index.php/rap/article/view/7140/569 2. Acesso em:25 nov. 2016.

REZENDE, D. A. Alinhamento do planejamento estratégico da tecnologia da informação ao planejamento empresarial: proposta de um modelo e verificação da prática em grandes empresas brasileiras. 2002. 278 f. Tese (Doutorado em Engenharia de Produção). Universidade Federal de Santa Catarina, Florianópolis, 2002. Disponível em:

https: //repositorio.ufsc. br/xmlui/handle/123456789/83083. Acesso em: 05 dez. 2016.

RIBEIRO, C. F. A.O acesso à informação nos arquivos: o acesso à informação no quadro de desenvolvimento dos arquivos em Portugal.1998. 786f. Tese (Doutorado em Arquivística) - Faculdade de Letras, Universidade do Porto, Porto, 1998. Disponível em: https://repositorioaberto.up.pt/bitstream/10216/7058/3/fribeirovol01000061435.pdf. Acesso em: 03 dez. 2016.

RIBEIRO, A. E. Modelo de gestão estratégica para uma instituição confessional de ensino superior fundamentado no Balanced Scorecard. 2003. Dissertação (Mestrado em Engenharia de Produção) - Universidade Federal de Santa Catarina, Florianópolis, 2003. Disponível em: https://repositorio.ufsc. br/xmlui/handle/123456789/85094. Acesso em: 01 set. 2016.

ROCCO, B. C. B. Um estudo sobre gestão de documentos arquivísticos digitais na Administração Pública Federal brasileira. 2013. 130 f. Dissertação (Mestrado em Ciência da Informação), Universidade Federal do Rio de Janeiro, Rio de Janeiro, 2013. Disponível em: https://ridi.ibict.br/handle/123456789/711. Acesso em: 17 out. 2016.

RODRIGUES, A. M. L. A teoria dos arquivos e a gestão de documentos, Perspectivas em Ciência da Informação, Belo Horizonte, v. 11 n. 1, p. 
102-117, jan. 2006. Disponível em:

http://www.scielo.br/pdf/pci/v11n1/v11n1a09. Acesso em: 01 mai. 2016.

RONCAGLIO, C.; SZVARÇA, D. R.; BOJ ANOSKI, S. F. Arquivos, gestão de documentos e informação. Encontros BIBLI: R. Eletr. Bibl. Ci. Inf., Florianópolis, n. especial, jul. 2004. Disponível em:

https: // periodicos.ufsc. br/index.php/eb/article/view/1518-

2924.2004v9nesp2p1/5486. Acesso em: 04 ago. 2016.

RONDINELLI, R. C. Gerenciamento arquivístico de documentos eletrônicos: uma abordagem teórica da diplomática arquivística contemporânea. 4. ed. Rio de Janeiro: FGV, 2005. 160 p.

SAMPAIO, M. I. C.; FONTES, C. DE A.; REBELLO, M. A. DE F. R..; ZANI., R. M. F.; BARREIROS, A. DE A.; PRADO, A. M. M.C.; CORDEIRO, E. C.L.; VILLELA, M. C. PAQ- Programa de avaliação da qualidade de produtos e serviços de informação: uma experiência no SIBi/USP, Ciência da informação, v. 33, n. 1, p. 142-148, 2004. Disponível em: http://revista.ibict. br/ciinf/article/view/1078. Acesso em: 18 ago. 2016.

SANTOS, T. B. S. Desenvolvimento financeiro e crescimento econômico. Estratégica, [S.I.], v. 9, n. 8, p. 103-114, jun. 2010. Disponível em: http://estrategica.faap.br/ojs/index.php/estrategica/article/view/19. Acesso em: 14 abr. 2016.

SANTOS, H. M.; FLORES, D. Preservação de documentos arquivísticos digitais: reflexões sobre as estratégias de emulação, Encontros Bibli: Revista Eletrônica de Biblioteconomia e Ciência da Informação, [S.I], v. 20, n. 43, p. 3-19, mai. 2015. Disponível em: https: //periodicos.ufsc. br/index.php/eb/article/view/15182924.2015v20n43p3. Acesso em: 22 jun. 2016.

SILVA, F; FLEURY, M. T. L. Cultura organizacional e tecnologia de informação: um estudo de caso em organizações universitárias. In: Informática, organizações e sociedade no Brasil. São Paulo: Cortez, 2003. p. 161-183.

SILVA, R. C. P.; SANTOS, A. G.; VIEIRO, T. V. Políticas arquivísticas para implantação de um sistema de arquivos e gestão documental na Universidade Federal de Rio Grande (FURG). In: CONGRESO DE ARCHIVOLOGÍA DEL MERCOSUR, 8./REUNIÓN DE ARCHIVOS UNIVERSITÁRIOS, 6., 2009, Montevidéu. Anais[...]. Montevidéu: Associação dos Arquivistas Uruguaios e o Arquivo Geral da Nação, 2009. Disponível em: https://periodicos.furg.br/biblos/article/view/2253. Acesso em: 18 ago. 2016. 
SOARES, A. P. A. Avaliação da qualidade em serviços de arquivos. 2012. 326 f. Dissertação (Mestrado em Ciências da I nformação), Universidade Federal de Santa Catarina, Florianópolis, 2012. Disponível em: https://periodicos. ufsc. br/index.php/eb/article/view/27274. Acesso em: 04 ago. 2016.

SOARES, C. Modelo de sistema auxiliar de avaliação para Instituição de Ensino Superior.2003.Dissertação (Programa de Pós-graduação em Engenharia de Produção), Universidade Federal de Santa Catarina, Florianópolis, 2003. Disponível em:

https://repositorio.ufsc.br/handle/123456789/85914. Acesso em: 06 ago. 2016.

SOUZA, R. T. B. Classificação de documentos arquivísticos: trajetória de um conceito, Arquivística.net, Rio de Janeiro, v.2, n. 2, p 120-142, ago. 2006. Disponível em:

https://repositorio.unb.br/bitstream/10482/948/2/ARTIGO_ClassificacaoD ocumentoArquivistico.pdf. Acesso em: 17 out. 2016.

SOUZA, A. E.; CORREA, H. L. Indicadores de desempenho em pequenas e médias empresas, RPCA, Rio de Janeiro, v. 8, n. 3, p. 118-136, jul., 2014. Disponível em: https://periodicos.uff.br/pca/article/view/11185. Acesso em: 28 set. 2016 .

TEIXEIRA, C. M. S.; SCHIEL, U.A Internet e seu impacto nos processos de recuperação da informação, Ciência da Informação, v. 26, n. 1, 1997. Disponível em: http://revista.ibict.br/ciinf/article/view/754. Acesso em: 19 jul. 2016.

TONELlO, I. M. S.; NUNES, R. M. da S.; PANARO, A. P. Prontuário do paciente: a questão do sigilo e a lei de acesso à informação, Informação \& informação, v. 18, n. 2, p. 193-210, 2013. Disponível em:

http://www.uel. br/revistas/uel/index.php/informacao/article/view/16169/ 13097. Acesso em: 04 ago. 2016.

TRIVINOS, A. N. S. Introdução à pesquisa em Ciência Sociais: a pesquisa qualitativa em educação. São Paulo: Atlas, 1987.

ZANI NELLI, T. B.; TOMAÉL, M. I.; J OVANOVICH, E. M. S.; LOURENÇO, R. F.; REIS, E. V. Os nativos digitais e as bibliotecas universitárias: um paralelo entre o novo perfil do usuário e os produtos e serviços informacionais, Inf. Inf., Londrina, v. 21, n. 3, p. 149 - 184, set. /dez. 2016. Disponível em:

http://www.uel.br/revistas/uel/index.php/informacao/article/view/25861/ 20733. Acesso em: 18 ago. 2016. 
WU, Ing-Long; CHEN, Jian-Liang. A stage-based diffusion of IT innovation and the BSC performance impact: a moderator of technologyorganization-environment, Technological Forecasting and Social Change, [s.l.], n. 88, p. 76-90, 2014. Disponível em: https://www.sciencedirect.com/science/article/pii/S0040162514002054. Acesso em: 07 fev. 2016.

Yin R. Estudo de caso: planejamento e métodos. 2. ed. Porto Alegre: Bookman, 2001. 